\title{
Lewis Acid Catalyzed Enantioselective Photochemical Rearrangements on the Singlet Potential Energy Surface
}

\author{
Malte Leverenz, ${ }^{\dagger}$ Christian Merten, ${ }^{\ddagger(0)}$ Andreas Dreuw, ${ }^{\S(0)}$ and Thorsten Bach ${ }^{*}{ }^{\dagger} \odot$ \\ ${ }^{\dagger}$ Department Chemie and Catalysis Research Center (CRC), Technische Universität München, Lichtenbergstraße 4, 85747 \\ Garching, Germany \\ ${ }^{\ddagger}$ Fakultät für Chemie und Biochemie, Ruhr-Universität Bochum, Universitätsstraße 150, 44801 Bochum, Germany \\ ${ }^{\S}$ Interdisciplinary Center for Scientific Computing, Ruprecht-Karls Universität, Im Neuenheimer Feld 205A, 69120 Heidelberg, \\ Germany
}

\section{Supporting Information}

\begin{abstract}
The oxadi- $\pi$-methane rearrangement of 2,4-cyclohexadienones to bicyclic ketones was found to proceed with high enantioselectivity $(92-97 \% e e)$ in the presence of catalytic amounts of a chiral Lewis acid (15 examples, $52-80 \%$ yield). A notable feature of the transformation is the fact that it proceeds on the singlet hypersurface and that no triplet intermediates are involved. Rapid racemic background reactions were therefore avoided, and the catalyst loading could be kept low $(10 \mathrm{~mol} \%)$. Computational studies suggest that the enantioselectivity is determined within a Lewis acid bound singlet intermediate via a conical intersection. The utility of the method was demonstrated by a concise synthesis of the natural product trans-chrysanthemic acid.
\end{abstract}

$\mathrm{T}$ he construction of a complex molecular skeleton in a single step is arguably the most fascinating hallmark of photochemical transformations. The high energy content of a light-excited substrate enables the formation of bonds which are not accessible by thermal methods. ${ }^{1,2}$ Although photoredox catalysis has opened several new avenues for enantioselective synthesis via ground state intermediates, ${ }^{3,4}$ the control of competing enantiomorphic reaction pathways in the excited state continues to pose a formidable challenge. After seminal contributions to the field in the past decades of the 20th century, ${ }^{5,6}$ recent efforts toward catalytic enantioselective photochemical reactions in solution ${ }^{7-9}$ have mainly aimed at the formation of cyclobutanes by $[2+2]$ photocycloaddition reactions. ${ }^{10-16}$ Our group has exploited chiral Lewis acids in this context, ${ }^{17-19}$ and we found that reversible coordination to an enone substrate I (Scheme 1) leads to a bathochromic shift of the allowed $\pi \pi^{*}$ transition (absorption coefficient $\varepsilon>$ $10000 \mathrm{M}^{-1} \mathrm{~cm}^{-1}$ ). Excitation of complex I.L.A.* at a long wavelength generates via a singlet intermediate $\left(S_{1}\right)$ the reactive $\pi \pi^{*}$ triplet state $\left(\mathrm{T}_{1}\right)$. Since intersystem crossing (ISC) from $\pi \pi^{*}$ to $\pi \pi^{*}$ is slow while ISC from $n \pi^{*}$ to $\pi \pi^{*}$ is fast, ${ }^{20}$ the catalyzed reaction is retarded. ${ }^{21}$ As a result, the uncatalyzed reaction initiated by direct irradiation of $\mathbf{I}$ via its $\mathrm{n} \pi^{*}$ state becomes competitive which in turn requires a high Lewis acid loading (50 mol \%) to secure high enantioselectivities.
Scheme 1. Photochemical Reactivity Modes of Complexes between a Chiral Lewis Acid (L.A.*) and a Substrate

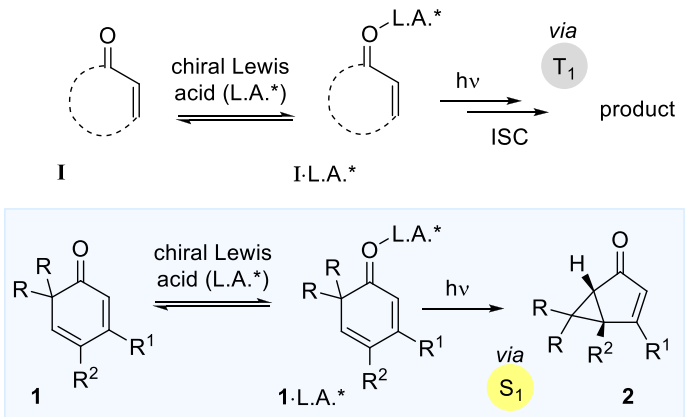

When searching for enone reactions which would occur from the $S_{1}$ state we came across a study by Griffith and Hart that dealt with the photochemical behavior of substituted 2,4cyclohexadienones $1 .^{22}$ It had been found that the typical triplet reaction observed for this substrate class was suppressed in polar media and that an oxadi- $\pi$-methane rearrangement ${ }^{23,24}$ occurred. In a later study by Uppili and Ramamurthy, ${ }^{25}$ the photochemical rearrangement of a single 2,4-cyclohexadienone was performed within a zeolite and an enantiomeric excess (ee) of up to $49 \%$ was achieved with (-)-ephedrine as a superstoichiometric (10 equiv) inductor at $-55{ }^{\circ} \mathrm{C}$. We hypothesized that complexation of substrates $\mathbf{1}$ with a chiral Lewis acid would lead to a complex 1.L.A.* which would upon direct excitation generate enantiomerically enriched products 2 via a singlet intermediate. We now report on our studies in this area which have led to the first catalytic enantioselective ${ }^{26}$ oxadi- $\pi$-methane rearrangement. ${ }^{27}$

Initial experiments were conducted with 2,4-cyclohexadienone 1a, the absorption properties of which were examined in the absence and in the presence of Lewis acids (Figure 1). Successive addition of $\mathrm{BF}_{3} \cdot \mathrm{OEt}_{2}$ to a solution of the compound in dichloromethane $(c=2 \mathrm{mM})$ led to a shift of the $\pi \pi^{*}$ band $\left(\lambda=310 \mathrm{~nm}, \varepsilon=5380 \mathrm{M}^{-1} \mathrm{~cm}^{-1}\right)$. Due to coordination of $\mathrm{BF}_{3}$ to the oxygen lone pair, the $\mathrm{n} \pi^{*}$ absorption (shoulder at $\lambda=$ $365 \mathrm{~nm}, \varepsilon=335 \mathrm{M}^{-1} \mathrm{~cm}^{-1}$ ) vanished. A new band appeared at $\lambda=360 \mathrm{~nm}$ which was assigned to the $\pi \pi^{*}$ transition of the

Received: November 8, 2019

Published: December 8, 2019 


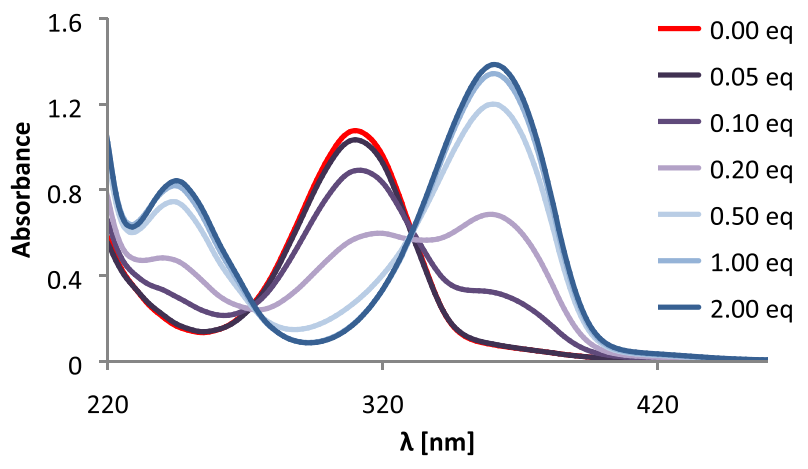

Figure 1. UV/vis spectra of 2,4-cyclohexadienone 1a in the absence and in the presence of different equivalents of $\mathrm{BF}_{3} \cdot \mathrm{OEt}_{2}(c=2 \mathrm{mM}$ in $\left.\mathrm{CH}_{2} \mathrm{Cl}_{2}, \mathrm{rt}\right)$.

Lewis acid complex $\mathbf{1 a} \cdot \mathrm{BF}_{3}$. Assuming the complex formation to be complete upon addition of 2 equiv of the Lewis acid, the absorption coefficient was calculated as $\varepsilon=6920 \mathrm{M}^{-1} \mathrm{~cm}^{-1}$. Isosbestic points at $\lambda=272 \mathrm{~nm}$ and at $\lambda=330 \mathrm{~nm}$ indicate that no other species contribute to the absorption spectra except for 1a and $\mathbf{1 a} \cdot \mathrm{BF}_{3}$. Similar spectra were obtained with $\mathrm{EtAlCl}_{2}$ as the Lewis acid (Figure S1).

In general, the absorption difference of complexed vs uncomplexed enones $\Delta \lambda$ (in $\mathrm{nm}$ ) increases if the original $\pi \pi^{*}$ absorption of the chromophore occurs at higher wavelength. For 2,4-cyclohexadienone 1a, the absorption maximum of complex 1a.EtAlCl 2 was at $\lambda=368 \mathrm{~nm}$ with $\Delta \lambda=58 \mathrm{~nm}$. Compared with other enones, which absorb at a shorter wavelength, the shift was larger. ${ }^{18,19}$ Together with the expectation of a singlet reaction pathway, an enantioselective transformation even at low Lewis acid catalyst loading seemed therefore feasible.

The fact that the Lewis acid induced shift tailed into the visible region (Figure 1) invited a reaction with visible light. While irradiation of $1 \mathrm{a}$ at $\lambda=420 \mathrm{~nm}$ in the absence of a Lewis acid did not lead to a detectable conversion (for details, see Table S1), $10 \mathrm{~mol} \%$ of $\mathrm{BF}_{3}$ as the Lewis acid induced the expected rearrangement. The product was formed as a 1:1 mixture of the two enantiomers $2 \mathbf{a}$ and ent-2a, i.e. as the racemate (Scheme 2). At $\lambda=420 \mathrm{~nm}$, neither the product nor its $\mathrm{BF}_{3}$ complex shows a detectable absorption and secondary photochemical reactions are avoided (Figure S2).

Scheme 2. Lewis Acid Catalyzed Photochemical

Rearrangement 1a $\rightarrow$ 2a and ent-2a
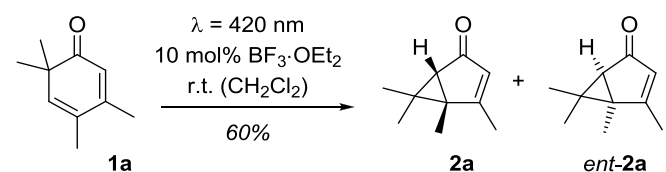

Having established a catalytic protocol for the oxadi- $\pi$ methane rearrangement of substrate 1a, we started to screen potential chiral Lewis acids. The screening commenced with typical $\mathrm{AlBr}_{3}$-activated oxazaborolidines which we had previously used for enantioselective photochemical reactions. ${ }^{17-19}$ They are derived from bis(3,5-dimethylphenyl)-2pyrrolidinyl-methanol and prepared by condensation with a boronic acid. ${ }^{19,28}$ However, it turned out that the enantioselectivities remained unsatisfactory $(<50 \% e e)$ which forced us to consider variations of the aryl groups at the methanol carbon atom. Catalyst 3 (Table 1 ) with sterically bulky $3^{\prime}, 5^{\prime}$ dimethyl-2-biphenyl groups as aryl substituents both at the carbon and at the boron atom evolved from these experiments as the superior Lewis acid that promoted the reaction $\mathbf{1 a} \rightarrow \mathbf{2 a}$ at $\lambda=420 \mathrm{~nm}\left(10 \mathrm{~mol} \%,-75{ }^{\circ} \mathrm{C}\right.$ in $\left.\mathrm{CH}_{2} \mathrm{Cl}_{2}\right)$ in a yield of $60 \%$ with $85 \%$ ee. Optimization of the irradiation conditions led to an improved performance if a light emitting diode (LED) with an emission maximum at $\lambda=437 \mathrm{~nm}$ was employed (Figures S4-S8). Product 2a was obtained in $68 \%$ yield with $92 \% e e$. The absolute configuration of the product was established by vibrational circular dichroism (VCD), ${ }^{29}$ comparing experimental and calculated spectra (for details, see Figures S9, S10). The absolute configuration of the other products 2 was assigned based on analogy. The assignment is supported by the identical direction of the specific rotation for all compounds (dextrorotatory) and was later confirmed by a natural product synthesis (vide infra). It was possible to extend the method to a large variety of 3-alkyl substituted 2,4cyclohexadienones $(\mathbf{1} \mathbf{b}-\mathbf{1 0})$ which had not been previously employed for the reaction (Table 1 ). The enantioselectivity remained consistently high $(>90 \%$ ee $)$ with yields varying between $52 \%$ and $86 \%$. The reaction is compatible with functional groups as demonstrated for aryl (product $\mathbf{2 g}$ ), alkenyl (2h), methoxy (2i, $2 \mathbf{j})$, chloro (2k), acyloxy (2l), trifluoromethyl $(\mathbf{2 m})$, and protected amino $(\mathbf{2 n})$.

Products $\mathbf{2}$ display several sites for further functionalization and lend themselves to potential use in synthesis. The gemdimethyl substituted cyclopropane ring is a notable feature in terpene natural products, and the monoterpene transchrysanthemic acid seemed to be a viable target (Scheme 3). Employing an oxidative cleavage protocol, ${ }^{30}$ we could successfully convert oxadi- $\pi$-methane rearrangement product $2 \mathrm{j}$ into acid 4 without loss of enantiopurity (93\% ee). Since the projected $\mathrm{Ni}$-catalyzed coupling step ${ }^{31}$ was known to proceed in low yield, we synthesized the starting material $2 \mathbf{j}$ on larger scale $(100 \mathrm{mg})$ confirming that the photochemical reactions can be run successfully at a higher concentration (Table 1 ). After conversion to the $N$-tetrachlorophthaloyl (NTCP) derivative, the coupling ${ }^{31}$ was performed without isolation of the intermediate. The reaction produced the trans-compound 5 (d.r. > 95/5) with a consistent enantiopurity of $93 \%$ ee. The stereogenic center at $\mathrm{C} 1$ is retained in this operation while the stereogenic center at C3 is inverted. Saponification of the ester delivered acid $\mathbf{6}$ as the levorotatory enantiomer which is known to be $(1 S, 3 S)$-configured. ${ }^{32}$ The synthesis consequently supports the previous assignment of the absolute configuration for photoproduct $\mathbf{2} \mathbf{j}$.

The reaction $\mathbf{1 a} \rightarrow \mathbf{2 a}$ was performed under otherwise unchanged conditions (Table 1 ) in the presence of up to 10 equiv of piperylene which is an established triplet quencher. ${ }^{33}$ There was no decrease in rate or yield for product 2a indicating that triplet intermediates are not involved in the reaction (for details, see Figures S11, S12). The hypothesis that the reaction proceeds via a singlet intermediate was further supported by quantum chemical calculations using density functional theory (DFT) as well as spin-flip linearresponse time-dependent DFT (TDDFT) $)^{34,35}$ as implemented into Q-Chem 5.0. ${ }^{36}$ It was found that the Lewis acid complex $1 \mathrm{a} \cdot \mathrm{BF}_{3}$ reaches the first excited singlet state $\left(S_{1}\right)$ by an allowed $\pi \pi^{*}$ transition. Remarkably, the preferred conformation of this intermediate is not planar but the gem-dimethylated carbon atom $\mathrm{C} 6$ bends out of the plane in which the remaining five carbon atoms reside (Figure 2). The $\mathrm{C} 1-\mathrm{C} 5$ distance has a 
Table 1. Enantioselective Photochemical Rearrangement $1 \rightarrow 2$ Mediated by Chiral Lewis Acid 3
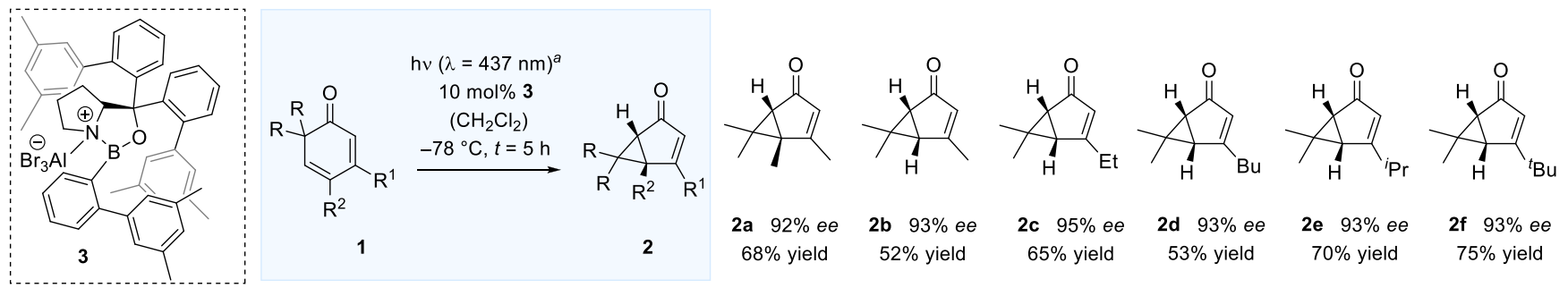
2c $95 \%$ ee
$65 \%$ yield

2d $93 \%$ ee

$53 \%$ yield $\quad 70 \%$ yield

$2 f 93 \%$ ee $68 \%$ yield

$52 \%$ yield

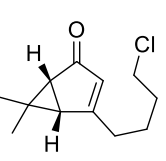

2k $93 \%$ ee

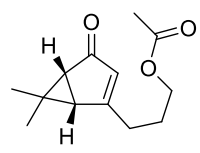

21 $92 \%$ ee

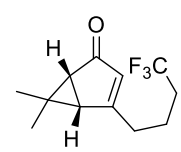

2 m $92 \%$ ee

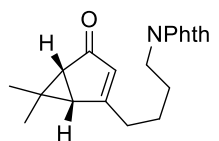

2n $97 \%$ ee $60 \%$ yield

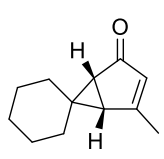

2o $96 \%$ ee $80 \%$ yield

${ }^{a}$ Reactions were carried out on a $150 \mu \mathrm{mol}$ scale at a concentration of $c=20 \mathrm{mM}$. ${ }^{b}$ The reaction was carried out on a $750 \mu \mathrm{mol}$ scale at a concentration of $c=100 \mathrm{mM}$ and at a wavelength of $\lambda=425 \mathrm{~nm}$ for $24 \mathrm{~h} .{ }^{c} \mathrm{Phth}=$ phthaloyl.

Scheme 3. Enantioselective Total Synthesis of transChrysanthemic Acid (6)
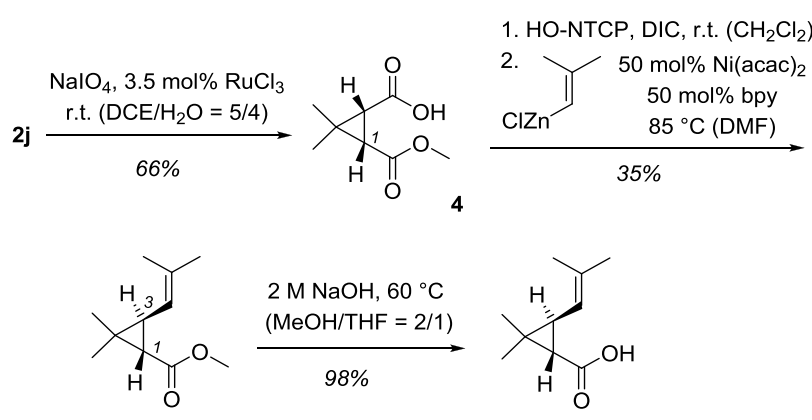

$5(93 \%$ ee $)$

6

${ }^{a}$ Acac $=$ acetylacetone; bpy $=2,2^{\prime}$-bipyridine; DCE $=1,2$-dichloroethane, DIC $=N, N^{\prime}$-dicarbonyldiimide; $\mathrm{DMF}=\mathrm{N}, \mathrm{N}$-dimethylformamide; $\mathrm{Me}=$ methyl; NTCP $=N$-tetrachlorophthaloyl; $\mathrm{THF}=$ tetrahydrofuran.

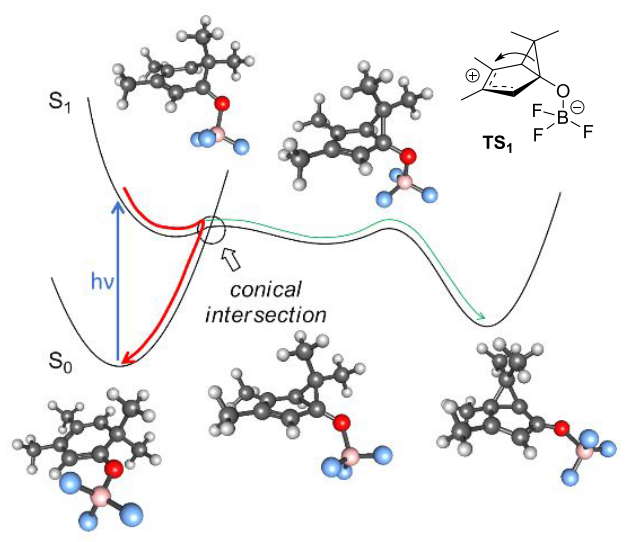

Figure 2. Reaction mechanism of the photochemical rearrangement illustrated for substrate 1a.

value of $218 \mathrm{pm}$ at the equilibrium geometry of the $S_{1}$ state. Proceeding along the relaxation pathway, a sloped conical intersection is energetically accessible only $0.09 \mathrm{eV}$ above the minimum structure, which predominantly leads to relaxation back to the ground state $S_{0}$. At the optimized geometry of the conical intersection, the critical $\mathrm{C} 1-\mathrm{C} 5$ distance decreases to only $193 \mathrm{pm}$. Those molecules not returning to the electronic ground state enter the productive exit channel that proceeds via an intermediate zwitterion now with a $\mathrm{C} 1-\mathrm{C} 5$ bond length of $150 \mathrm{pm}$. Thereby, the conical intersection avoids the population of triplet states and secures a clean product formation with however low quantum yield. The $\mathrm{C}-\mathrm{C}$ bond formation between carbon atoms $\mathrm{C} 1$ and $\mathrm{C} 5$ occurs via the trajectory predetermined by the bending of carbon atom C6. The reaction is completed by a typical 1,4-migration of the cyclopropyl group via $\mathbf{T S}_{1}$ to the cationic carbon atom, which proceeds via a small energy barrier of $0.15 \mathrm{eV}$ leaving the complex of product $\mathrm{rac}-\mathbf{2} \mathbf{a} \cdot \mathrm{BF}_{3}$ as the final reaction product.

The calculation also provides a plausible explanation for the observed enantioselectivity. Bending of carbon atom C6 out of the dienone plane in complex 1a.L.A. leads after C-C bond formation to two enantiomeric intermediates 7 and ent-7 which in turn deliver products $\mathbf{2 a}$ and ent-2a (Figure 3).

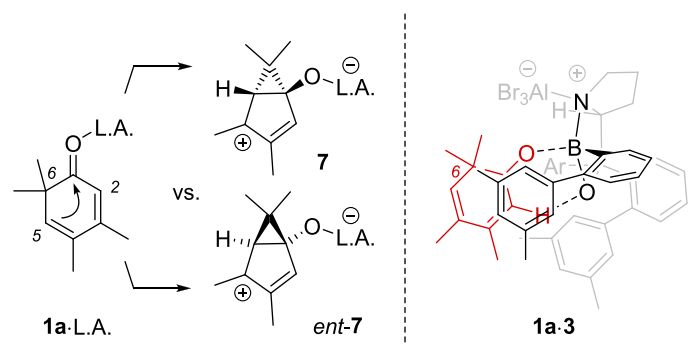

Figure 3. Migration of carbon atom C5 in Lewis acid complex 1a.L.A. as the enantioselectivity-determining step leading to either enantiomer 7 or ent-7.

Coordination of compound $\mathbf{1}$ a to oxazaborolidine Lewis acids is assumed to occur as previously established for cyclic enones. ${ }^{37-39}$ In the presence of chiral Lewis acid 3, there is a preference for formation of intermediate 7 because the C6 carbon atom in complex 1a.3 will not move in the direction of the bulky $3^{\prime}, 5^{\prime}$-dimethyl-2-biphenyl substituent at the boron atom but will bend away from it. Product formation via intermediate 7 leads to enantiomer $2 \mathrm{a}$ by 1,4 -migration. The importance of the hydrogen bond at carbon atom C2 to the oxygen atom of the catalyst was corroborated in the present 
study by the fact that a 2-methyl-substituted 2,4-cyclohexadienone did not react enantioselectively (Figure S13).

In summary, we have discovered an enantioselective photochemical rearrangement reaction that enables the rapid formation of structurally unique, multifunctional products. A remarkable feature of the transformation is the fact that Lewis acid coordination opens a reaction channel that allows the substrate to escape intersystem crossing via a conical intersection. In addition, the Lewis acid governs the absolute configuration of the product within a singlet intermediate. This mode of action promises to be a useful design element for enantioselective photocatalysis.

\section{ASSOCIATED CONTENT}

\section{S Supporting Information}

The Supporting Information is available free of charge at https://pubs.acs.org/doi/10.1021/jacs.9b12068.

Experimental procedures, analytical data and NMR spectra for all new compounds, GLC and HPLC traces of chiral products, VCD data, Cartesian coordinates, including Figures S1-S13, Table S1 (PDF)

\section{AUTHOR INFORMATION}

\section{Corresponding Author}

*thorsten.bach@ch.tum.de

\section{ORCID $\odot$}

Christian Merten: 0000-0002-4106-1905

Andreas Dreuw: 0000-0002-5862-5113

Thorsten Bach: 0000-0002-1342-0202

\section{Notes}

The authors declare no competing financial interest.

\section{ACKNOWLEDGMENTS}

Financial support by the European Research Council under the European Union's Horizon 2020 research and innovation programme (Grant Agreement No. 665951 - ELICOS) is gratefully acknowledged. C.M. thanks the Fonds der chemischen Industrie for a Liebig fellowship and the Deutsche Forschungsgemeinschaft for support through the Cluster of Excellence RESOLV ("Ruhr Explores SOLVation", EXC 2033). We thank O. Ackermann and J. Kudermann for their help with the HPLC and GLC analyses.

\section{REFERENCES}

(1) Photochemistry of Organic Compounds: From Concepts to Practice; Klán, P., Wirz, J., Eds.; Wiley: Chichester, U.K., 2009.

(2) Kärkäs, M. D.; Porco, J. A., Jr.; Stephenson, C. R. J. Photochemical Approaches to Complex Chemotypes: Applications in Natural Product Synthesis. Chem. Rev. 2016, 116, 9683-9747.

(3) Visible Light Photocatalysis in Organic Chemistry; Stephenson, C. R. J., Yoon, T. P., MacMillan, D. W. C., Eds.; Wiley-VCH: Weinheim, 2018.

(4) Silvi, M.; Melchiorre, P. Enhancing the potential of enantioselective organocatalysis with light. Nature 2018, 554, 41-49.

(5) Inoue, Y.; Yokoyama, T.; Yamasaki, N.; Tai, A. An optical yield that increases with temperature in a photochemically induced enantiomeric isomerization. Nature 1989, 341, 225-226.

(6) Inoue, Y. Asymmetric Photochemical Reactions in Solution. Chem. Rev. 1992, 92, 741-770.

(7) Sherbrook, E. M.; Yoon, T. P. Asymmetric Catalysis of TripletState Photoreactions. Photochemistry 2018, 46, 432-447.
(8) Garrido-Castro, A. F.; Maestro, M. C.; Alemán, J. Asymmetric induction in photocatalysis - Discovering a new side to light-driven chemistry. Tetrahedron Lett. 2018, 59, 1286-1294.

(9) Brimioulle, R.; Lenhart, D.; Maturi, M. M.; Bach, T. Enantioselective Catalysis of Photochemical Reactions. Angew. Chem., Int. Ed. 2015, 54, 3872-3890.

(10) Müller, C.; Bauer, A.; Bach, T. Light-driven Enantioselective Organocatalysis. Angew. Chem., Int. Ed. 2009, 48, 6640-6642.

(11) Du, J. N.; Skubi, K. L.; Schultz, D. M.; Yoon, T. P. A DualCatalysis Approach to Enantioselective $2+2$ Photocycloadditions Using Visible Light. Science 2014, 344, 392-396.

(12) Vallavoju, N.; Selvakumar, S.; Jockusch, S.; Sibi, M. P.; Sivaguru, J. Enantioselective Organo-Photocatalysis Mediated by Atropisomeric Thiourea Derivatives. Angew. Chem., Int. Ed. 2014, 53, $5604-5608$

(13) Blum, T. R.; Miller, Z. D.; Bates, D. M.; Guzei, I. A.; Yoon, T. P. Enantioselective photochemistry through Lewis acid-catalyzed triplet energy transfer. Science 2016, 354, 1391-1395.

(14) Tröster, A.; Alonso, R.; Bauer, A.; Bach, T. Enantioselective Intermolecular $[2+2]$ Photocycloaddition Reactions of 2(1H)Quinolones Induced by Visible Light Irradiation. J. Am. Chem. Soc. 2016, 138, 7808-7811.

(15) Huang, X.; Quinn, T. R.; Harms, K.; Webster, R. D.; Zhang, L.; Wiest, O.; Meggers, E. Direct Visible-Light-Excited Asymmetric Lewis Acid Catalysis of Intermolecular [2+2] Photocycloadditions. J. Am. Chem. Soc. 2017, 139, 9120-9123.

(16) Zheng, J.; Swords, W. B.; Jung, H.; Skubi, K. L.; Kidd, J. B.; Meyer, G. J.; Baik, M.-H.; Yoon, T. P. Enantioselective Intermolecular Excited-State Photoreactions Using a Chiral Ir Triplet Sensitizer: Separating Association from Energy Transfer in Asymmetric Photocatalysis. J. Am. Chem. Soc. 2019, 141, 13625-13634.

(17) Guo, H.; Herdtweck, E.; Bach, T. Enantioselective Lewis Acid Catalysis in Intramolecular $[2+2]$-Photocycloaddition Reactions of Coumarins. Angew. Chem., Int. Ed. 2010, 49, 7782-7785.

(18) Brimioulle, R.; Bach, T. Enantioselective Lewis Acid Catalysis of Intramolecular Enone $[2+2]$ Photocycloaddition Reactions. Science 2013, 342, 840-843.

(19) Poplata, S.; Bach, T. Enantioselective Intermolecular $[2+2]$ Photocycloaddition Reaction of Cyclic Enones and its Application in a Synthesis of (-)-Grandisol. J. Am. Chem. Soc. 2018, 140, 32283231.

(20) El-Sayed, M. A. Triplet state. Its radiative and nonradiative properties. Acc. Chem. Res. 1968, 1, 8-16.

(21) Brimioulle, R.; Bauer, A.; Bach, T. Enantioselective Lewis Acid Catalysis in Intramolecular $[2+2]$ Photocycloaddition Reactions: A Mechanistic Comparison between Representative Coumarin and Enone Substrates. J. Am. Chem. Soc. 2015, 137, 5170-5176.

(22) Griffiths, J.; Hart, H. A New General Photochemical Reaction of 2,4-Cyclohexadienones. J. Am. Chem. Soc. 1968, 90, 5296-5298.

(23) Banwell, M. G.; Bon, D. J.-Y. D. Applications of Di- $\pi$-Methane and Related Rearrangement Reactions in Chemical Synthesis. In Molecular Rearrangements in Organic Synthesis; Rojas, C. M., Ed.; Wiley: Hoboken, NJ, 2015; pp 261-288.

(24) Riguet, E.; Hoffmann, N. Di- $\pi$-methane, Oxa-di- $\pi$-methane, and Aza-di- $\pi$-methane Photoisomerization. In Comprehensive Organic Synthesis, 2nd ed.; Knochel, P., Molander, G. A., Eds.; Elsevier: Amsterdam, 2014; Vol. 5, pp 200-221.

(25) Uppili, S.; Ramamurthy, V. Enhanced Enantio- and Diastereoselectivities via Confinement: Photorearrangement of 2,4Cyclohexadienones Included in Zeolites. Org. Lett. 2002, 4, 87-90.

(26) For a recent review on catalytic enantioselective rearrangement reactions, see: Wu, H.; Wang, Q.; Zhu, J. Recent Advances in Catalytic Enantioselective Rearrangement. Eur. J. Org. Chem. 2019, 2019, 1964-1980.

(27) For previous work on an enantioselective oxadi- $\pi$-methane rearrangement (up to $10 \% e e$ ), see: Demuth, M.; Raghavan, P. R.; Carter, C.; Nakano, K.; Schaffner, K. Photochemical High-yield Preparation of Tricyclo[3.3.0.0 $\left.0^{2,8}\right]$ octan-3-ones. Potential Synthons 
for Polycyclopentanoid Terpenes and Prostacyclin Analogs. Helv. Chim. Acta 1980, 63, 2434-2439.

(28) Corey, E. J.; Shibata, T.; Lee, T. W. Asymmetric Diels-Alder Reactions Catalyzed by a Triflic Acid Activated Chiral Oxazaborolidine. J. Am. Chem. Soc. 2002, 124, 3808-3809.

(29) Merten, C.; Golub, T. P.; Kreienborg, N. M. Absolute Configurations of Synthetic Molecular Scaffolds from Vibrational CD Spectroscopy. J. Org. Chem. 2019, 84, 8797-8814.

(30) Yang, D.; Zhang, C. Ruthenium-Catalyzed Oxidative Cleavage of Olefins to Aldehydes. J. Org. Chem. 2001, 66, 4814-4818.

(31) Edwards, J. T.; Merchant, R. R.; McClymont, K. S.; Knouse, K. W.; Qin, T.; Malins, L. R.; Vokits, B.; Shaw, S. A.; Bao, D.-H.; Wei, F.L.; Zhou, T.; Eastgate, M. D.; Baran, P. S. Decarboxylative alkenylation. Nature 2017, 545, 213-218.

(32) Begley, M. J.; Crombie, L.; Simmonds, D. J.; Whiting, D. A. Absolute Configuration of the Pyrethrins. Configuration and Structure of (+)-Allethronyl (+)-trans-Chrysanthemate 6-Bromo2,4-dinitrophenylhydrazone by X-ray Methods. J. Chem. Soc., Chem. Commun. 1972, 1276-1277.

(33) Hammond, G. S.; Saltiel, J.; Lamola, A. A.; Turro, N. J.; Bradshaw, J. S.; Cowan, D. O.; Counsell, R. C.; Vogt, V.; Dalton, C. Mechanisms of Photochemical Reactions in Solution. XXII. Photochemical cis-trans Isomerization. J. Am. Chem. Soc. 1964, 86, 31973217.

(34) Shao, Y.; Head-Gordon, M.; Krylov, A. I. The spin-flip approach within time-dependent density functional theory: Theory and applications to diradicals. J. Chem. Phys. 2003, 118, 4807-4818.

(35) Dreuw, A.; Head-Gordon, M. Single-Reference ab Initio Methods for the Calculation of Excited States of Large Molecules. Chem. Rev. 2005, 105, 4009-4037.

(36) Shao, Y.; Gan, Z.; Epifanovsky, E.; Gilbert, A. T. B.; Wormit, M.; Kussmann, J.; Lange, A. W.; Behn, A.; Deng, J.; Feng, X.; Ghosh, D.; Goldey, M.; Horn, P. R.; Jacobson, L. D.; Kaliman, I.; Khaliullin, R. Z.; Kuś, T.; Landau, A.; Liu, J.; Proynov, E. I.; Rhee, Y. M.; Richard, R. M.; Rohrdanz, M. A.; Steele, R. P.; Sundstrom, E. J.; Woodcock, H. L.; Zimmerman, P. M.; Zuev, D.; Albrecht, B.; Alguire, E.; Austin, B.; Beran, G. J. O.; Bernard, Y. A.; Berquist, E.; Brandhorst, K.; Bravaya, K. B.; Brown, S. T.; Casanova, D.; Chang, C.-M.; Chen, Y.; Chien, S. H.; Closser, K. D.; Crittenden, D. L.; Diedenhofen, M.; DiStasio, R. A.; Do, H.; Dutoi, A. D.; Edgar, R. G.; Fatehi, S.; FustiMolnar, L.; Ghysels, A.; Golubeva-Zadorozhnaya, A.; Gomes, J.; Hanson-Heine, M. W. D.; Harbach, P. H. P.; Hauser, A. W.; Hohenstein, E. G.; Holden, Z. C.; Jagau, T.-C.; Ji, H.; Kaduk, B.; Khistyaev, K.; Kim, J.; Kim, J.; King, R. A.; Klunzinger, P.; Kosenkov, D.; Kowalczyk, T.; Krauter, C. M.; Lao, K. U.; Laurent, A. D.; Lawler, K. V.; Levchenko, S. V.; Lin, C. Y.; Liu, F.; Livshits, E.; Lochan, R. C.; Luenser, A.; Manohar, P.; Manzer, S. F.; Mao, S.-P.; Mardirossian, N.; Marenich, A. V.; Maurer, S. A.; Mayhall, N. J.; Neuscamman, E.; Oana, C. M.; Olivares-Amaya, R.; O’Neill, D. P.; Parkhill, J. A.; Perrine, T. M.; Peverati, R.; Prociuk, A.; Rehn, D. R.; Rosta, E.; Russ, N. J.; Sharada, S. M.; Sharma, S.; Small, D. W.; Sodt, A.; Stein, T.; Stück, D.; Su, Y.-C.; Thom, A. J. W.; Tsuchimochi, T.; Vanovschi, V.; Vogt, L.; Vydrov, O.; Wang, T.; Watson, M. A.; Wenzel, J.; White, A.; Williams, C. F.; Yang, J.; Yeganeh, S.; Yost, S. R.; You, Z.-Q.; Zhang, I. Y.; Zhang, X.; Zhao, Y.; Brooks, B. R.; Chan, G. K. L.; Chipman, D. M.; Cramer, C. J.; Goddard, W. A.; Gordon, M. S.; Hehre, W. J.; Klamt, A.; Schaefer, H. F.; Schmidt, M. W.; Sherrill, C. D.; Truhlar, D. G.; Warshel, A.; Xu, X.; Aspuru-Guzik, A.; Baer, R.; Bell, A. T.; Besley, N. A.; Chai, J.-D.; Dreuw, A.; Dunietz, B. D.; Furlani, T. R.; Gwaltney, S. R.; Hsu, C.-P.; Jung, Y.; Kong, J.; Lambrecht, D. S.; Liang, W.; Ochsenfeld, C.; Rassolov, V. A.; Slipchenko, L. V.; Subotnik, J. E.; Van Voorhis, T.; Herbert, J. M.; Krylov, A. I.; Gill, P. M. W.; HeadGordon, M. Advances in molecular quantum chemistry contained in the Q-Chem 4 program package. Mol. Phys. 2015, 113, 184-215.

(37) Paddon-Row, M. N.; Anderson, C. D.; Houk, K. N. Computational Evaluation of Enantioselective Diels-Alder Reactions Mediated by Corey's Cationic Oxazaborolidine Catalysts. J. Org. Chem. 2009, 74, 861-868.
(38) Sakata, K.; Fujimoto, H. Quantum Chemical Study of DielsAlder Reactions Catalyzed by Lewis Acid Activated Oxazaborolidines. J. Org. Chem. 2013, 78, 3095-3103.

(39) Poplata, S.; Bauer, A.; Storch, G.; Bach, T. Intramolecular [2+ 2] Photocycloaddition of Cyclic Enones: Selectivity Control by Lewis Acids and Mechanistic Implications. Chem. - Eur. J. 2019, 25, 81358148 . 